\begin{tabular}{c} 
International Journal of Engineering \& Technology, $7(2.32)(2018) 60-63$ \\
SPC \\
International Journal of Engineering \& Technology \\
Website: $w w w$. sciencepubco.com/index.php/IJET \\
Research paper \\
\hline
\end{tabular}

\title{
Development of Research \& Development Dashboard For an University
}

\author{
Kodukula Subrahmanyam, Tirumuru Ketha, Salichemaladevarajulu Balakrishna, \\ Telaprolu Naga Manoj Kumar
}

K L E F (KLEF), Vaddeswaram, Guntur District, AP, India,

*Corresponding author E-mail: smkodukula@kluniversity.in

\begin{abstract}
An information dashboard is a data association gadget that ostensibly tracks, displays and demonstrates the principle key execution markers (KPI) and key information focuses to screen the soundness of a business, university, office or particular process. They are versatile to meet the specific needs of an office and company or an university. A dashboard interfaces with our documents, attachments, services and API's, yet at first look shows this information as tables and also used to monitor and track various data. As constant checking decreases the hours of breaking down an information dashboard is the most proficient approach to track numerous information. In Research and progression work is facilitated towards the innovation, introduction, and development and advancement of products and processes. In this project we are going to develop a framework for R\&D of a University in this we are mainly focusing on the Academic Research, sponsored \& Internal Funding Research, Consultancy, center of Excellence, Innovation Incubation \& Entrepreneurship and Extramural.This R\&D Dashboard is utilized for web based enlisting for patents, copyrights, licenses, copyrights, productions in meetings, sorting out gatherings, seminars and workshops. This Dashboard was developed, utilizing Windows-based Microsoft excel, VISUAL BASIC and back end is Microsoft Access Database. The VISUAL BASIC has easy to use pull down menus and toolbars for different analysis.
\end{abstract}

Keywords: Dashboard, University Administration, Research and Development, Innovation Incubation and Entrepreneurship, Extramural.

\section{Introduction}

Dashboard is used to represent all the data about an organization or department. They are adaptable to meet the particular needs of an office and company or an university. A dashboard interfaces with our documents, attachments, services and API's, yet at first look shows this information as tables and also used to monitor and track various data. Dashboard is the most proficient approach to track numerous information sources. Great basic leadership must be upheld by the speed of data accessibility and precision. In the event that where mistake data got happened, such occasion may give lethal effect to the basic leadership process itself. Accordingly, almost every association needs to use the data and innovation frameworks (called ICT) to help them picking up data rapidly and precisely. The huge aggregate of accessible information can be a test for associations to sort and procedure to be a more helpful data. To make the huge measure of information handling not meddle the current operational process, the Data Warehouse is the answer for it [1]. Dashboard application which will help us for the association to get to data asset as representation. This type of a visual data show will positively assist us with reading data rapidly and effortlessly. In Research and development work is coordinated towards the innovation, introduction, and development of products and processes. $R \& D$ intends to make new innovation or data that can enhance the viability of items or make the creation of items more productive. "Innovative work" ordinarily alludes to future-arranged, longerterm exercises in science or innovation, utilizing procedures without foreordained results and with wide conjectures of business yield [2]. In this project we are going to develop a framework for R\&D of a University in this we are mainly focusing on the Academic
Research, sponsored \& Internal Funding Research, Consultancy, center of Excellence, Innovation Incubation \& Entrepreneurship, Extramural. It also tells about the Year Wise Sponsored Research Projects Amount Received, Dept wise Sponsored Projects worth, Ongoing Projects Funded, UGC Research Awards, Department wise Young Scientist Projects, Department wise Women Scientist projects, Department wise Young Scientist Projects, DST-FIST Sponsored Departments, DST-FIST Sponsored Labs, R\&D Funding, Internal Funded Projects - Department Wise, Number of PhD's Registered, Ph.D students Registered-Department Wise, Publication Details these all details are represented in this Dashboard and this information can be tracked very efficiently through this Dashboard and some Extension Activities are involved like Science fairs, security Activities etc.

The R\&D cell of a university ought to be dynamic in enrolling for licenses, copyrights, productions in meetings, sorting out gatherings, seminars and workshops. Workforce and understudies have been urged to be innovative, since it is the inventive perspective that instigates more up to date considering. Research and development needs to authorize important assets for creative work.

\subsection{Universities achieve the following objectives by using this Dashboard}

1. To secure new logical learning.

2. To outline the novel methodologies in every single one of the fields of Engineering and Technology.

3. To develop the new strategies for advanced critical thinking for problem solving. 


\section{Literature Survey}

In this we discuss about various dashboards

\subsection{University of Texas (UT) System Dashboard}

It comprises a Dashboard having the structured presentation of various colleges which spends on research use in billions for NPHE systems. Regardless of savage, UT System establishments get an amazing level of subsidizing for look into UT System topped \$2.8 billion in inventive work (R\&D) utilizations. UT System positions second in the nation in R\&D utilizes among state supported school structures. School of Texas structure mainly focuses on Research Expenditures, Gross Revenue from Intellectual Property, New Invention Disclosures, U.S. Licenses Issued, Start up organizations shaped [8].

\subsection{AP CM Dashboard}

CM Dashboard contains the data about the government ongoing projects and the projects that are going to be implemented. It contains the data about the Financial status of the state. In the Agriculture and Allied areas tells about how much lakh Hectares is sown under Kharif and how much lakh Hectares is sown under normal seasons. It also deals with the data about civil supplies, excise Revenues in crore's and commercial taxes. It deals with the projects like NTR bharosa, Janma Bhumi, EODB and so on for under poverty people. It also contains another departments like Police, Registrations \& Stamps, Roads \& Buildings, water resources, tourism, Welfare department, Rural Development, School Education and so on [4].

\subsection{State Bank of India Dashboard}

State Bank of India (SBI) is an Indian multinational, open part dealing with a record and financial organization. In this Dashboard the top 500 Indian companies Financial statistics were displayed and they are updated frequently. The stock closing price is updated at the every month ending. It also gives the data about the income and expenses(in crores) for every year using bar graph. It also gives data about the shares etc. It contains the sales \& Major Expenditure (in crore) like
1. Admin Expenses
2. Multifarious Expenses
3. Employee cost
4. Integrity Dividend and so on [7].

\subsection{Prime Minister Dashboard}

PM Dashboard contains News Updates like daily cabinet news, cabinet approvals. Messages from the PM. Information about PM international and domestic visits, Information about government track records, Rundown of officers in PM office, PM speeches [5] [6].

\subsection{Research and Development Dashboard}

In this innovative work Dashboard for the most part mainly focuses on the significant issues at the core of the Group's business exercises like:- Urban development; Energy execution; Infrastructure manageability; Eco-outline; New portability administrations. This Dashboard also focuses on Media in the zones like official statements, News refresh, Social media, s, Apps, Media Library. This innovative work in the zones like Eco-plan and Sustainable urban communities, Collaborative advancement, $\mathrm{R} \& \mathrm{D}$ and Innovation [9].

\section{Existing System}

In this flow situation if the exploration points of interest is done physically the work is done on paper which causes blunder it requires greater investment to put subtle elements physically. The principle issue in this is the seeking of information takes additional time and causes a few mistakes. The copies additionally increments through this procedure.

\section{Proposed System}

The R\&D Dashboard is utilized for web based enlisting for patents, copyrights, licenses, copyrights, productions in meetings, sorting out gatherings, seminars and workshops [8]. Workforce and understudies have been urged to be imaginative, since it is the innovative angle that actuates more advanced. Through this proposed Dashboard the searching time will be minimized than the existing system and the duplication of data will not be there.

\section{Architecture}

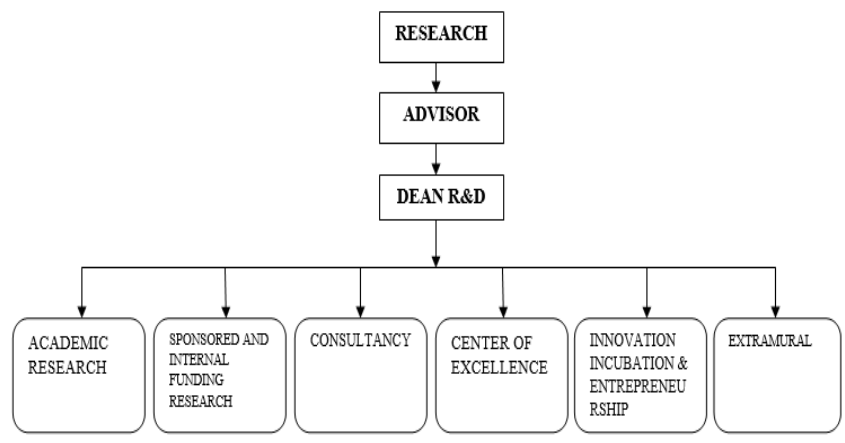

Fig.1: Basic architecture of the Dashboard

The proposed system integrates all various modules as shown in fig. 1 . It contains of different modules which are associated and handled centrally by proposed framework called as Research and Development Dashboard.

\section{Working}

This Dashboard is separated in some primary modules they are as per the following:

\subsection{Academic Research}

It contains faculty details, scholar details, projects list and the functions present here are:

i. Search by Guide :- If we enter guide employee id then it will show all the rundown of researchers working under him and the whole information about every researcher.

ii. Search by Scholar :- If we enter scholar id then it will display every one of the points of interest of the researcher including the guide details, projects list. guide subtle elements, ventures list.

iii. Search by Year :- In the event that we give from year and to year all extend points of interest in that period of this module will be shown the year might be academic year or financial year.

\subsection{Sponsored Research \& Internal Funding}

This module contains list of completed projects, list of ongoing projects, women scientist sponsored projects young scientist sponsored project, it also gives the data about events like science fair, faculty 
development programmers, travel grant, inspire camps etc and the agencies that are funding for ongoing or completed projects.

i. Search by PI:-If we enter PI id then it will display every one of the points of interest of that PI where ever he/she is involved in this module.

ii. Search by Year:- In the event that we give from year and to year all extend points of interest in that period of this module will be shown the year might be academic year or financial year.

\subsection{Consultancy}

It contains list of important consultancies undertaken by university in the last 4 to 5 years list of activities in coordination with industrial relation cell.

i. Search by Year:- In the event that we give from year and to year all extend points of interest in that period of this module will be shown the year might be academic year or financial year.

ii. Search by Department:- In this we need to choose the department name and select the event then it shows every one of the points of interest of that department for the event we have chosen.

\subsection{Centre of Excellence}

It contains of number of COE'S in existence and their details CEO activities in the selected month and proposals for new COE'S.

i. Search by Year:- In the event that we give from year and to year all extend points of interest in that period of this module will be shown the year might be academic year or financial year.

ii. Search by Department:- In this we need to choose the department name and select the event then it shows every one of the points of interest of that department for the event we have chosen.

\subsection{Innovation Incubation and Entrepreneurship}

It contains list of Entrepreneurship events details of innovation ideas\Point of interest submitted or registered by students or faculty, details of Startups initiated by students and faculty, details of Entrepreneurship students or faculty joined as members(CIIE).

i. Search by Year:- In the event that we give from year and to year all extend points of interest in that period of this module will be shown the year might be academic year or financial year.

ii. Search by Department:- In this we need to choose the department name and select the event then it shows every one of the points of interest of that department for the event we have chosen.

\subsection{Extramural Activities}

It contains points of interest of Extensional and Research exercises, Professional Society exercises, Student Society exercises and Conferences and Workshops and faculty who served as experts, chairpersons etc.

i. Search by Year:- In the event that we give from year and to year all extend points of interest in that period of this module will be shown the year might be academic year or financial year.

ii. Search by Department:- In this we need to choose the department name and select the event then it shows every one of the points of interest of that department for the event we have chosen.

\section{Results}

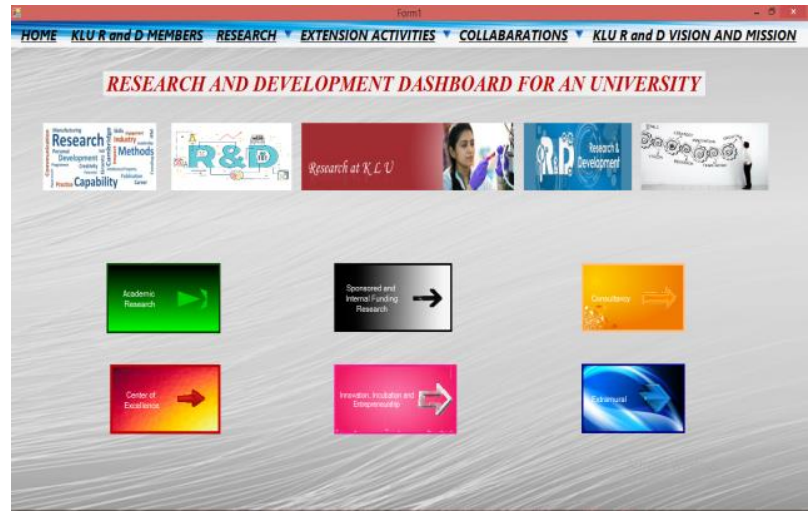

Fig.2 Research and Development Dashboard For an University

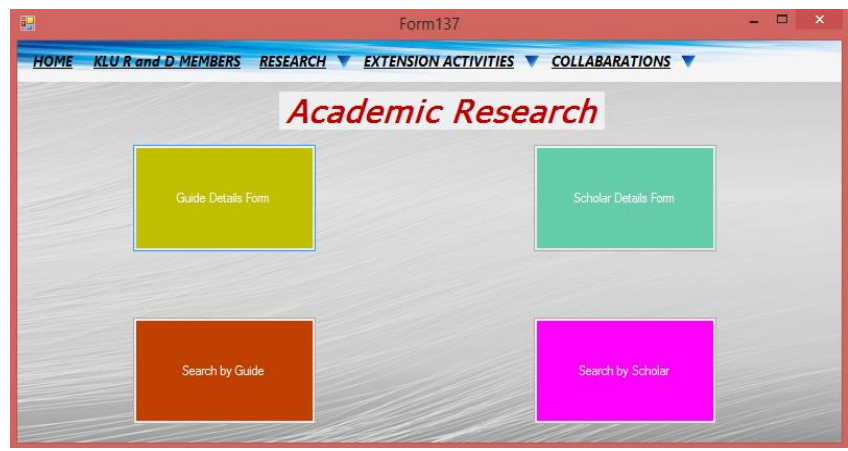

Fig.3 Academic Research

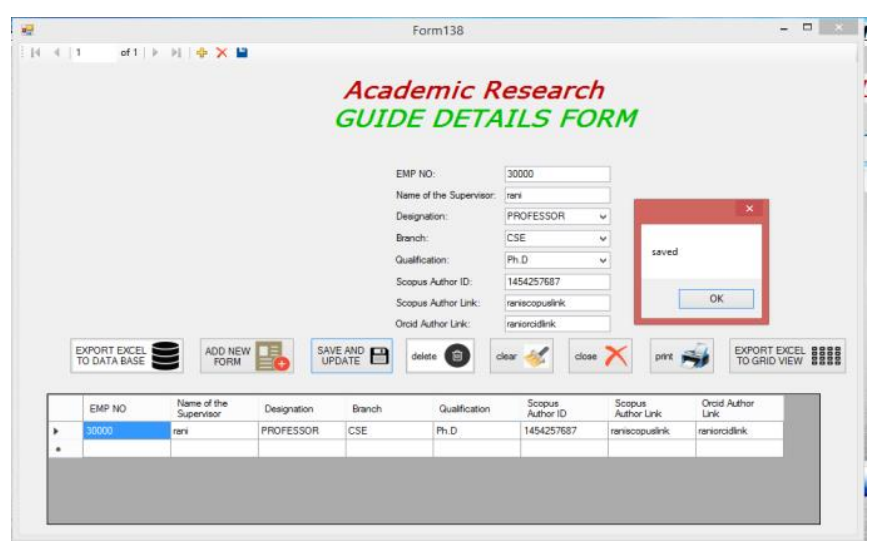

Fig.4 Academic Research with Guide Details

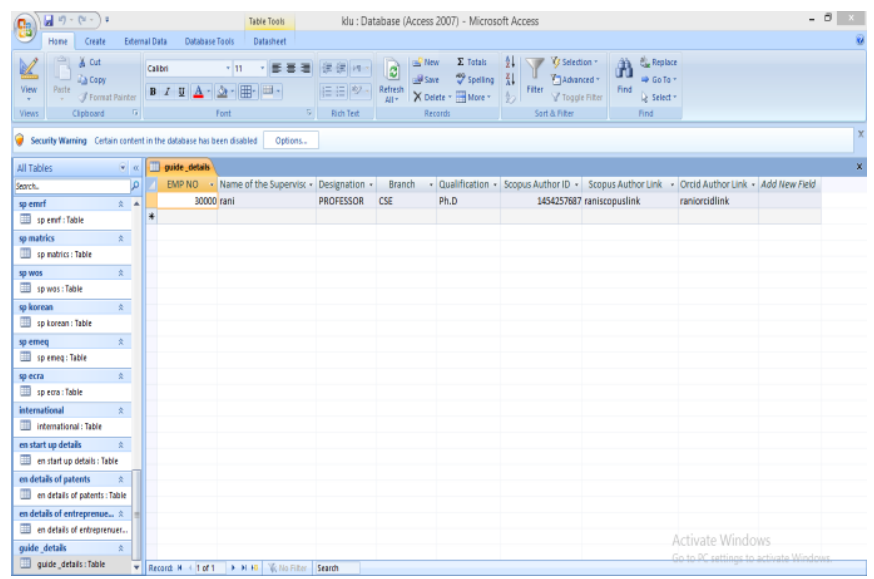

Fig.5 Guide Details into Database 


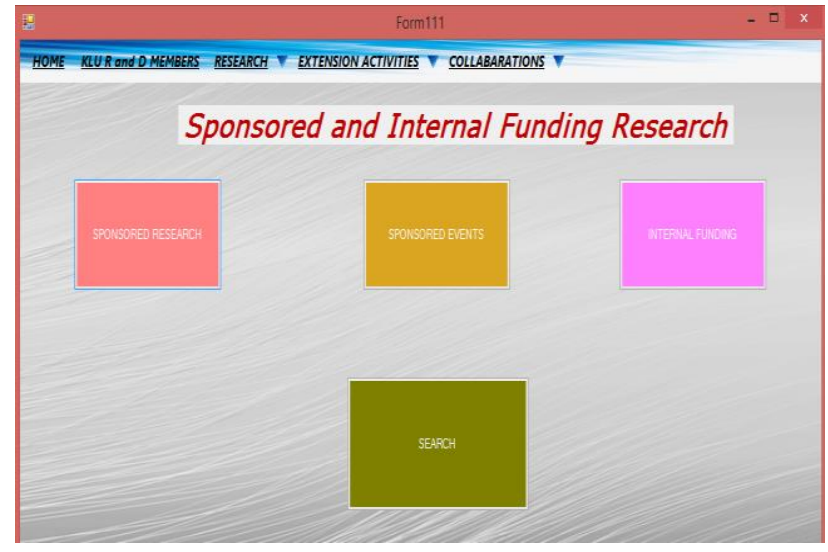

Fig:6 Sponsored and Internal Funding Research

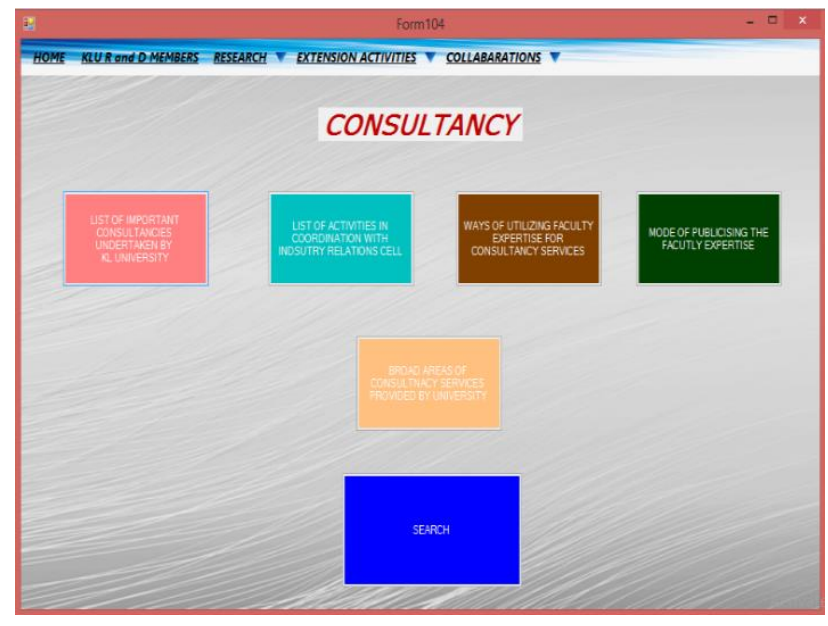

Fig:7 Consultancy

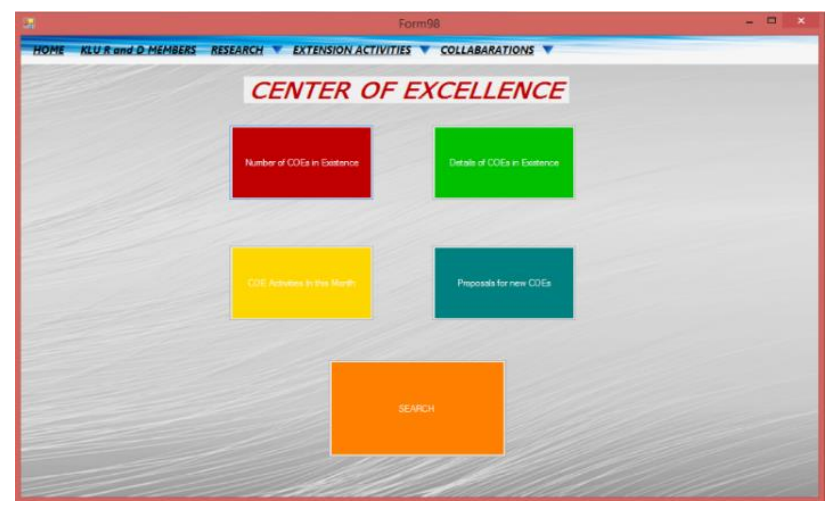

Fig:8 Center of Excellence

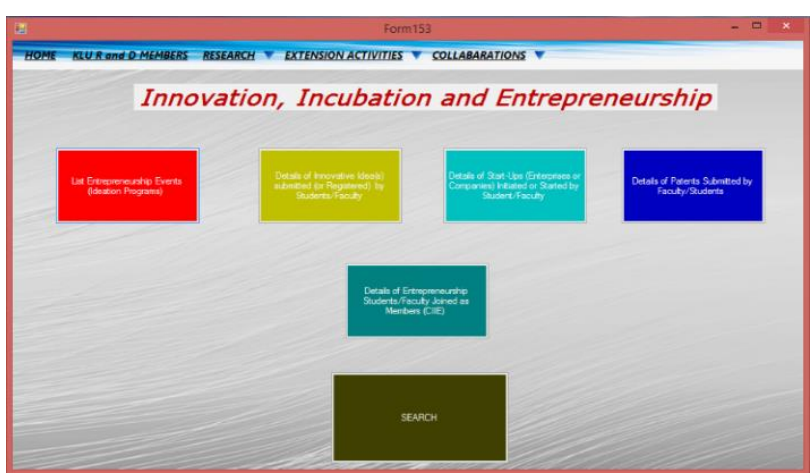

Fig:9 Innovation, Incubation and Entreprenuership

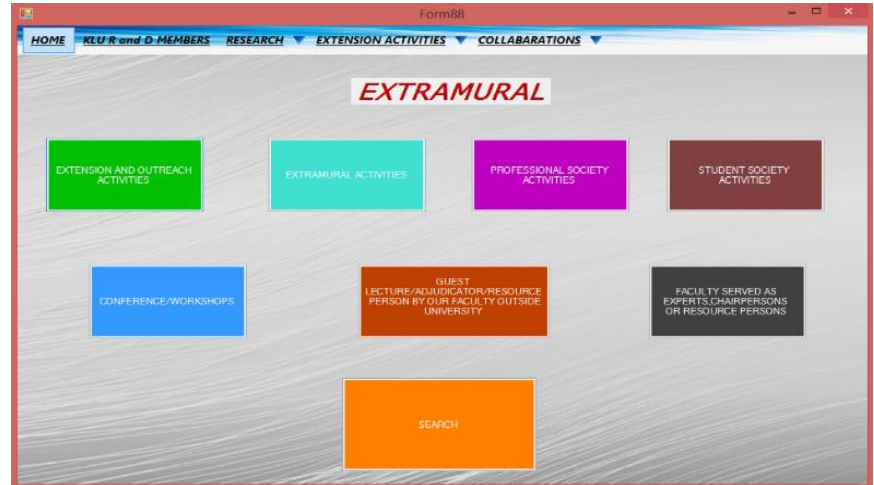

Fig.10 Extramural

\section{Conclusions}

The idea of Research and Development dashboard is confined, which will have distinctive highlights like online pursuit of guide points of interest, researcher subtle elements, different exercises directed by university like visitor addresses, meetings, social exercises, rundown of activities, supported task points of interest, diverse consultancies, COE's and funding agencies that are funding for project.

\section{References}

[1] "University Dashboard an Implementation of Executive Dashboard to University", by Meyliana, Henry A. E Widjaja, Stephen W. Santoso, 2nd International Conference on Information and Communication Technology (ICoICT), 2014..

[2] "Towards Textual Reporting in Learning Analytics Dashboards", A Ramos-Soto, M. Lama, B. Vazquez-Barreiros, A. Bugarın, M Mucientes, S. Barro, 15th International Conference on Advanced Learning Technologies, 2015.

[3] "Development and Application of Computer Software for Simulation of Vibration Analysis in Education", M. R. Askari and R. Davis, International Conference on SIMULATION , Conference Publication No.457,IEEE.

[4] http://www.core.ap.gov.in/CMDashBoard/Index.aspx

[5] http://www.pmindia.gov.in/en/governance-track-record/

[6] http://powermin.nic.in/

[7] https://knoema.com/uqevvsg/state-bank-of-india-financialdashboard

[8] https://data.utsystem.edu/metricdesc/research

[9] http://www.ucl.ac.uk/isd/services/research-it/researchsoftware/dashboard 